\title{
Airway bacteria and respiratory symptoms are common in ambulatory HIV-positive UK adults
}

\author{
To the Editor:
}

The widespread use of antiretroviral therapy (ART) and Pneumocystis pneumonia prophylaxis has led to significant declines in opportunistic infection rates in people with chronic HIV infection. Despite this, pulmonary disease is more common in these patients than HIV-negative individuals [1]. Observational studies suggest that while bacterial pneumonia is reduced by ART, it still occurs relatively frequently even after CD4 T-cell reconstitution [2,3]. Non-recurrent HIV-associated bacterial pneumonia is 10 times more likely than in uninfected individuals $[3,4]$, and is now the most common infection and the leading cause of death after sepsis [5].

HIV-positive individuals are particularly prone to invasive pneumococcal diseases (IPD), mainly pneumococcal pneumonia [6], which accounts for 40 per cent of all bacterial pneumonia where the aetiological agent is identified [3]. Haemophilus influenzae is the next most common cause [3]. Proposed explanations for the increased susceptibility to bacterial pneumonia include dysfunctional CD4 and CD8 T-cell responses, as well as the prevalence of lifestyle factors, such as smoking and injecting drug use in HIV-positive individuals [2].

In addition to the infectious complications of HIV, rates of obstructive airways disease are also higher. Studies in the USA have found that 16-20\% of HIV-positive individuals have asthma or chronic obstructive pulmonary disease (COPD), and poorly controlled HIV accelerates lung function decline [1]. In HIV-negative patients with COPD, one report identified lower airway bacterial colonisation (LABC) in $44 \%$ of stable-state COPD patients, and found it to be associated with increasing airway inflammation, frequency of exacerbations and lung function decline [7]. However, work from Malawi, as well as the UK, using traditional culture methods with protected specimen brushing and bronchoalveolar lavage respectively found no difference in the frequency of LABC in HIV-positive and negative healthy volunteers $[8,9]$.

To our knowledge the extent of LABC in HIV has not been examined using modern molecular techniques. In this study we evaluate respiratory symptoms and determine levels of common airway bacterial pathogens by quantitative PCR (qPCR) in a cohort of HIV-positive individuals.

A representative sample of patients receiving ambulatory HIV care at the Royal Free Hospital (London, UK) was recruited by stratified selection into a tuberculosis screening study between July 2013 and June 2014. A self-completed questionnaire was used to obtain medical and residential histories, lifestyle information (smoking, alcohol, injecting drug use), and respiratory symptom scores. Respiratory symptom questions included the following. 1) Have you had a cough in the last 4 weeks? 2) Do you ever wheeze? 3) Do you get breathless walking up one flight of stairs? 4) Do you get a cough (productive of sputum/phlegm) most winters?

Spirometry was performed in accordance with the European Respiratory Society guidelines and the percentage of predicted forced expiratory volume in $1 \mathrm{~s}$ was calculated. Current and nadir CD4 count, viral load and medication history were obtained from the hospital's electronic medical records and HIV database. Patients had frontal chest radiographs performed followed by sputum induction with $3.5 \%$ hypertonic saline.

DNA extraction and multiplex qPCR processing for airway bacteria (Streptococcus pneumoniae, H. influenzae, Moraxella catarrhalis, Legionella pneumophila, Chlamydia pneumoniae and Mycoplasma pneumoniae) were performed as previously described [7]. Data were analysed using SPSS v22 (IBM Inc., New York, NY, USA). Pearson's and Spearman's rank correlation, Chi-square, Fisher's exact test, Mann-Witney U-tests and t-tests were used as appropriate. A p-value $<0.05$ was taken to infer statistical significance. The study was approved by the National Research Ethics Services Committee London City and East (study number 12/LO/1516). All patients provided informed, written consent.

Demographic characteristics for the 218 originally enrolled patients and a subgroup of 53, who produced sufficient sputum for further analysis, were similar (table 1). The median blood CD4 count was 609 cells $\mu \mathrm{L}^{-1}$ and $84 \%$ had an HIV plasma load $<40$ copies. $\mathrm{mL}^{-1}$. The only statistically significant differences identified were that patients able to produce sputum were more likely to report a cough in the previous week $(p=0.04)$ and have a history of a winter cough $(\mathrm{p}=0.01)$. At least one respiratory symptom was given by $122(57 \%)$ out of 214 patients. 
TABLE 1 Baseline patient characteristics for the entire cohort and subgroup who produced sufficient sputum for bacterial investigations

\begin{tabular}{|c|c|c|c|c|c|}
\hline & \multirow[t]{2}{*}{ Entire cohort } & \multirow{2}{*}{$\begin{array}{l}\text { Subgroup with } \\
\text { sputum analysis }\end{array}$} & \multicolumn{2}{|c|}{ Bacteria } & \multirow{2}{*}{$\begin{array}{l}\mathrm{p} \text {-value for } \\
\text { interaction }\end{array}$} \\
\hline & & & Positive & Negative & \\
\hline Patients n & 218 & 53 & 23 & 30 & \\
\hline Age years & $46.7 \pm 9.8$ & $47.2 \pm 9.4$ & $48.1 \pm 8.5$ & $46.5 \pm 10.1$ & $>0.4$ \\
\hline \multicolumn{6}{|l|}{ Ethnicity } \\
\hline White British & $87 / 218$ (39.9) & $21 / 53(39.6)$ & $11 / 23(47.8)$ & 10/30 (33.3) & $>0.4$ \\
\hline \multicolumn{6}{|l|}{ Lifestyle } \\
\hline Ever smoker & $101 / 214(47.2)$ & $24 / 52(46.2)$ & $15 / 23$ (65.2) & $9 / 30(30.0)$ & 0.01 \\
\hline Current smoker & $49 / 214(22.9)$ & $14 / 52(26.9)$ & $11 / 23(47.8)$ & $3 / 30(10.0)$ & $<0.01$ \\
\hline Ever smoker pack-years & $16.8 \pm 14.5$ & $17.9 \pm 15.3$ & $19.1 \pm 16.0$ & $15.9 \pm 14.7$ & $>0.4$ \\
\hline Injecting drug use & $21 / 192(10.9)$ & $3 / 51(5.9)$ & $3 / 23(13.0)$ & $0 / 30(0.0)$ & 0.08 \\
\hline \multicolumn{6}{|l|}{ Respiratory health } \\
\hline Breathlessness & $67 / 211(31.8)$ & $17 / 52(32.7)$ & $9 / 23(39.1)$ & $8 / 30(26.7)$ & $>0.4$ \\
\hline Winter cough & $85 / 212(40.1)$ & $32 / 52(61.5)^{9}$ & $15 / 23(65.2)$ & $17 / 30(56.7)$ & $>0.4$ \\
\hline Previous PCP & $25 / 198(12.6)$ & $6 / 50$ (12.0) & $4 / 23(17.4)$ & $2 / 27(7.4)$ & 0.39 \\
\hline Previous bacterial pneumonia & $25 / 198(12.6)$ & $8 / 49(16.3)$ & $3 / 23(13.0)$ & $5 / 30(16.7)$ & $>0.4$ \\
\hline FEV $1 \%$ pred & $93.5 \pm 25.0$ & $92.1 \pm 18.5$ & $91.4 \pm 19.0$ & $92.6 \pm 18.5$ & $>0.4$ \\
\hline $\mathrm{FEV}_{1} / \mathrm{FVC}<0.7$ & $14 / 205$ (6.8) & $6 / 53(11.3)$ & $2 / 23(8.7)$ & $4 / 30(13.3)$ & $>0.4$ \\
\hline \multicolumn{6}{|l|}{ HIV management } \\
\hline Nadir CD4 T-cell count & $238(109-330)$ & $221(81-307)$ & $207(59-301)$ & 232 (95-327) & $>0.4$ \\
\hline Latest CD4 T-cell count & $609(447-784)$ & 707 (428-808) & $707(427-814)$ & 679 (418-807) & $>0.4$ \\
\hline \multicolumn{6}{|l|}{ ART } \\
\hline Currently using & $184 / 218(84.4)$ & 42/53 (79.2) & 17/23 (73.9) & $25 / 30$ (83.3) & $>0.4$ \\
\hline Previously used & 19/218 (8.7) & $7 / 53$ (13.2) & $4 / 23(17.4)$ & $3 / 30(10.0)$ & \\
\hline
\end{tabular}

Data are presented as $\mathrm{n} / \mathrm{N}(\%)$, mean $\pm \mathrm{SD}$, or median (interquartile range), unless otherwise stated. The subgroup that produced sputum is split into those with detectable bacteria (bacteria positive) and those without bacteria (bacteria negative) and the $p$-values for the differences between these two groups are shown. PCP: Pneumocystis pneumonia; FEV1; forced expiratory volume in $1 \mathrm{~s}$; FVC: forced vital capacity; ART: antiretroviral therapy. " : bacteria positive versus negative; ๆ: indicates significant differences.

Airway bacteria were present in $23(43 \%)$ out 53 samples. S. pneumoniae was the most commonly isolated species, in $16(30 \%)$ out of 53 samples, followed by $H$. influenzae in 10 (19\%) out of 53 samples and M. catarrhalis in $1(2 \%)$ out of 53 samples. None of the other bacterial species were detected. In samples where bacteria were isolated, mean \pm 1 SEM total bacterial load was $10^{5.8 \pm 0.2} \mathrm{CFU} \cdot \mathrm{mL}^{-1}$. Where $S$. pneumoniae or H. influenzae were found, the mean \pm SEM bacterial loads of these bacteria were $10^{6.4 \pm 0.2} \mathrm{CFU} \cdot \mathrm{mL}^{-1}$ and $10^{4.8}$ ${ }^{ \pm 0.2} \mathrm{CFU} \cdot \mathrm{mL}^{-1}$, respectively.

Patients with bacteria in their sputum were more likely to be smokers (table 1). This was also the case for S. pneumoniae in current smokers (detected in $6(16 \%)$ out of 37 smokers versus 8 (53\%) out of 15 nonsmokers, $\mathrm{p}=0.01)$ but not ever smokers (10 (63\%) out of 16 versus $14(39 \%)$ out of $36 ; \mathrm{p}=0.14)$. Patients reporting winter cough had a higher total bacterial load $(\mathrm{p}=0.04)$, while those reporting breathlessness had a trend to higher total bacterial load $(\mathrm{p}=0.05)$. Similarly, in patients where $S$. pneumoniae was identified, those reporting breathlessness had a higher $S$. pneumoniae bacterial load $(p=0.01)$. There was an inverse relationship between $S$. pneumoniae bacterial load and nadir CD4 count $(p=0.02)$. There were no other statistically significant associations with other measures of HIV control, respiratory symptoms, lifestyle factors (alcohol or injecting drug use) or lung function.

Our study shows that respiratory symptoms are common and, using nucleic acid amplification techniques, bacteria are often detected in induced sputum samples in an ambulatory HIV-positive cohort with 
generally good immune function. This is in contrast to previous studies that identified few bacteria in HIV patients using traditional culture techniques $[8,9]$, and suggests that the enhanced sensitivity afforded by tests for genetic material is an important consideration for future work.

The frequency of bacterial isolation in patients with HIV (43\%) is similar to that in HIV-negative patients with stable-state COPD (44\%) [7], where LABC is associated with increased exacerbation frequency [10] and long-term lung function decline [11]. Mean bacterial load in samples where bacteria were isolated from HIV patients was lower than in the COPD cohort $\left(10^{5.8 \pm 0.2}\right.$ versus $\left.10^{7.3 \pm 0.2} \mathrm{CFU} \cdot \mathrm{mL}^{-1} ; \mathrm{p}<0.01\right)$. However, comparison is difficult as sputum from HIV patients would have been diluted by saline used for induction whilst COPD patients produced sputum spontaneously.

Published descriptions of bacterial colonisation in healthy individuals generally come from comparisons of bronchoalveolar lavage or epithelial brushing culture in COPD patients and a control group. The reported frequency of LABC in healthy individuals varies from $10 \%$ to $27 \%$ and in COPD patients from $43 \%$ to $83 \%$ [12-14]. We found that smokers were more likely to have LABC, which is consistent with previous findings from a small study that showed airways colonisation levels were lower in healthy nonsmokers (13\%) than healthy smokers (40\%) and patients with COPD (62\%) [14].

In keeping with high rates of pneumococcal disease in HIV-positive individuals, S. pneumoniae was the most common colonising species (compared to $H$. influenzae in COPD patients). There was also an inverse correlation between $S$. pneumoniae bacterial load and nadir CD4 count, consistent with previous findings of more invasive pneumococcal disease in those with a nadir CD4 count under 200 even after access to ART [15].

We found bacterial load to be associated with a history of breathlessness and winter cough, but not other respiratory symptoms or spirometry. However, a properly powered study is needed to confirm this.

In this study we investigated the six most likely bacterial species to cause disease as surrogates for bacterial infection. We did not have matched nasal swabs, so were unable to assess nasopharyngeal bacterial colonisation or presence of viruses. It is possible that induced sputum may have been contaminated by upper airway bacteria. A study in Malawi, comparing S. pneumoniae airway colonisation in nasal and oral swabs, found S. pneumoniae to be present in 1 (4\%) out of $27 \mathrm{HIV}$-positive patients and 5 (23\%) out of 22 HIV-negative patients sampled. S. pneumoniae was also cultured from the right main bronchus brushings in one HIV-positive patient, but not from distal airway brushings [8].

Patients who could provide sputum $(n=53)$ were more likely to report a cough. This may represent a source of bias, though both the complete cohort $(n=218)$ and this subgroup had similar demographics, smoking history and spirometry; and reported a high overall frequency of respiratory symptoms.

The development of novel techniques, such as bacterial 16S pyrosequencing, now means it is possible to rapidly identify a wide range of bacteria from body sites, including the lung [16]. The Lung HIV Microbiome Project [17] is currently the largest study of this type and may further our understanding of the interaction between the host and microbiome in HIV-related respiratory health.

Our study demonstrates that pathogenic airway bacteria, in particular S. pneumoniae, are common in HIV-positive individuals with apparently good systemic immunity using ART. Quantitation indicates that there were higher levels of bacteria in smokers. Longitudinal studies could determine if LABC in the context of HIV leads to lung function decline in a similar manner to that found with COPD. We hypothesise that LABC contributes to the development of HIV-associated lung disease and provides a reservoir from which IPD may arise. Hence, testing for and targeting persistent airway bacteria, plus aggressive smoking cessation programmes, may be important strategies to combat long-term HIV-related morbidity.

@ERSpublications

Airway bacterial colonisation and respiratory symptoms are common in ambulatory HIV-positive UK adults http://ow.ly/Nug5A

Camus Nimmo $^{1}$, Santino Capocci ${ }^{1,2}$, Isobella Honeyborne ${ }^{3}$, James Brown ${ }^{1,2}$, Janey Sewell ${ }^{1}$, Sarah Thurston ${ }^{3}$, Margaret Johnson $^{2}$, Timothy D. McHugh ${ }^{3}$ and Marc Lipman ${ }^{1,2}$

${ }^{1}$ Division of Medicine, University College London, London, UK. ${ }^{2}$ Centre for Respiratory Medicine and Dept of Medicine, Royal Free London NHS Foundation Trust, London, UK. ${ }^{3}$ Centre for Clinical Microbiology, Division of Infection and Immunity, University College London, London, UK.

Correspondence: Marc Lipman, Centre for Respiratory Medicine, Royal Free London NHS Foundation Trust, Pond Street, London, NW3 2QG, UK. E-mail: marclipman@nhs.net

Received: March 052015 | Accepted after revision: May 042015 | First published online: June 252015

Conflict of interest: None declared. 


\section{References}

1 Drummond MB, Kirk GD. HIV-associated obstructive lung diseases: insights and implications for the clinician. Lancet Respir Med 2014; 2: 583-592.

2 Brown J, Lipman M. Community-acquired pneumonia in HIV-infected individuals. Curr Infect Dis Rep 2014; 16: 397.

3 Feikin DR, Feldman C, Schuchat A, et al. Global strategies to prevent bacterial pneumonia in adults with HIV disease. Lancet Infect Dis 2004; 4: 445-455.

4 Benito N, Moreno A, Miro JM, et al. Pulmonary infections in HIV-infected patients: an update in the 21st century. Eur Respir J 2012; 39: 730-745.

5 Kim JH, Psevdos G, Gonzalez E, et al. All-cause mortality in hospitalized HIV-infected patients at an acute tertiary care hospital with a comprehensive outpatient HIV care program in New York City in the era of highly active antiretroviral therapy (HAART). Infection 2013; 41: 545-551.

6 Jordano Q, Falcó V, Almirante B, et al. Invasive pneumococcal disease in patients infected with HIV: still a threat in the era of highly active antiretroviral therapy. Clin Infect Dis 2004; 38: 1623-1628.

7 Garcha DS, Thurston SJ, Patel AR, et al. Changes in prevalence and load of airway bacteria using quantitative PCR in stable and exacerbated COPD. Thorax 2012; 67: 1075-1080.

8 Gordon SB, Musaya J, Wilson L, et al. HIV infected adults do not have an excess of colonising bacteria in their large airways. BMC Infect Dis 2003; 3: 29.

9 Lipman MC, Ainscough S, Deery AR, et al. Infrequency of pulmonary microbial colonisation prior to respiratory disease in HIV-infected individuals. Eur J Clin Microbiol Infect Dis 2000; 19: 699-703.

10 Patel IS, Seemungal TA, Wilks M, et al. Relationship between bacterial colonisation and the frequency, character, and severity of COPD exacerbations. Thorax 2002; 57: 759-764.

11 Wilkinson TM, Patel IS, Wilks M, et al. Airway bacterial load and FEVı decline in patients with chronic obstructive pulmonary disease. Am J Respir Crit Care Med 2003; 167: 1090-1095.

12 Cabello H, Torres A, Celis R, et al. Bacterial colonization of distal airways in healthy subjects and chronic lung disease: a bronchoscopic study. Eur Respir J 1997; 10: 1137-1144.

13 Weinreich UM, Korsgaard J. Bacterial colonisation of lower airways in health and chronic lung disease. Clin Respir J 2008; $2: 116-122$.

14 Tumkaya M, Atis S, Ozge C, et al. Relationship between airway colonization, inflammation and exacerbation frequency in COPD. Respir Med 2007; 101: 729-737.

15 Siemieniuk RA, Gregson DB, Gill MJ. The persisting burden of invasive pneumococcal disease in HIV patients: an observational cohort study. BMC Infect Dis 2011; 11: 314.

16 Morris A, Beck JM, Schloss PD, et al. Comparison of the respiratory microbiome in healthy nonsmokers and smokers. Am J Respir Crit Care Med 2013; 187: 1067-1075.

17 Cui L, Lucht L, Tipton L, et al. Topographic diversity of the respiratory tract mycobiome and alteration in HIV and lung disease. Am J Respir Crit Care Med 2015; 191: 932-942.

\section{Nasal decongestant exposure in patients with pulmonary arterial hypertension: a pilot study}

To the Editor:

In the scientific and medical community, it is recognised that exposure to certain drugs could promote the development of pulmonary arterial hypertension (PAH). These drugs, with a "class effect" (amphetamine-like) or not (dasatinib), are prescribed for serious (dasatinib, interferons) or moderate (benfluorex) pathologies and do not induce PAH in all patients [1-9]. As a result, assessment of drug history exposure from PAH patients has become essential for providing optimal disease management [10].

Nasal decongestants are a class of drugs used by nasal or oral route for symptomatic treatment of nasal obstruction. Some of them have a chemical structure similar to amphetamine, as had been observed for fenfluramine derivatives [11]. According to the French national agency for medicines and health products safety, the mean annual sales of nasal decongestants between 2008 and 2011 in France were respectively (all specialties combined): 17.5 million boxes per year for systemic/oral and 19.3 million of units per year for nasal decongestants. Despite the fact that nasal decongestants are largely used, these drugs are not trivial and induce rare but serious cardiovascular or neurological side effects [12]. Phenylpropanolamine, also known as norephedrine, is a drug of the phenethylamine chemical class with a structure similar to amphetamine [13]. Phenylpropanolamine was used as a stimulant, nasal decongestant, and also as an anorectic agent. The study of pulmonary hypertension in America (SOPHIA) carried out between 1998 